\title{
Influence of material degradation on weld seam quality in hot gas butt welding of polyamides
}

\author{
Max Bialaschik ${ }^{1}$ (D) Volker Schöppner $^{1} \cdot$ Mirko Albrecht $^{2} \cdot$ Michael Gehde $^{2}$
}

Received: 3 November 2020 / Accepted: 4 March 2021 / Published online: 19 March 2021

(C) The Author(s) 2021

\begin{abstract}
The joining of plastics is required because component geometries are severely restricted in conventional manufacturing processes such as injection molding or extrusion. In addition to established processes such as hot plate welding, infrared welding, or vibration welding, hot gas butt welding is becoming more and more important industrially due to its advantages. The main benefits are the contactless heating process, the suitability for glass fiber reinforced, and high-temperature plastics as well as complex component geometries. However, various degradation phenomena can occur during the heating process used for economic reasons, due to the presence of oxygen in the air and to the high gas temperatures. In addition, the current patent situation suggests that welding with an oxidizing gas is not permissible depending on the material. On the other hand, however, there is experience from extrusion welding, with which long-term resistant weld seams can be produced using air. Investigations have shown that the same weld seam properties can be achieved with polypropylene using either air or nitrogen as the process gas. Experimental investigations have now been carried out on the suitability of different gases with regard to the weld seam quality when welding polyamides, which are generally regarded as more prone to oxidation. The results show that weld strengths are higher when nitrogen is used as process gas. However, equal weld strengths can be achieved with air and nitrogen when the material contains heat stabilizers.
\end{abstract}

Keywords Hot gas butt welding $\cdot$ Hot gas welding $\cdot$ Polymer joining $\cdot$ Polyamide

\section{Introduction}

In industry, glass fiber reinforced and high-temperature plastics are often joined by infrared welding [1], since the particle formation that occurs during vibration welding is no longer desired or permitted in production [2]. The challenges in infrared welding lie in the selection of a suitable emitter system as well as in the complex emitter-material interactions during melting of the joining partners. The usage of quartz glass emitters is limited by the complexity of the weld seam geometry, since the manufacturing of a contour-

Recommended for publication by Commission XVI - Polymer Joining and Adhesive Technology

Max Bialaschik

max.bialaschik@ktp.upb.de

1 Kunststofftechnik Paderborn (KTP), Paderborn University, Paderborn, Germany

2 Professorship of Plastics Engineering, Chemnitz University of Technology, Chemnitz, Germany following emitter system is not feasible with tight radii and high contour jumps. Metal foil emitters can be designed to follow the contours, but the electrical heating circuits must be separated, otherwise there is a risk of short circuit. Therefore, overlaps and closed weld seams can only be realized to a limited extent and often lead to an inhomogeneous melting behavior of the seam geometry [3, 4]. Also, hot plate welding is often no alternative due to the melt adhesion to the heating element, the temperature limit of the coating (approx. $270^{\circ} \mathrm{C}$ ) [5], and the damage of the non-stick coatings by reinforcing fibers [6]. For these reasons, hot gas butt welding, another non-contact heating process, is becoming increasingly widespread in industry [7].

\section{Motivation}

\subsection{Hot gas butt welding}

Hot gas butt welding is a two-stage, contactless welding process with a process sequence similar to infrared welding. The process starts with the placing of the 
two joining parts into the part fixtures. In the subsequent heating phase, the required melt layer thickness is plasticized with the aid of a heated process gas which is directed onto the surface of the joining seam through nozzles adapted to the component geometry. In industry, round nozzles are mainly used in rows as nozzle geometry, as they are more flexible than slotted nozzles and their design is also less complex. However, slotted nozzles achieve a better visual and mechanical weld seam quality $[8,9]$. The convective heat transfer is additionally overlaid by heat radiation emitted by the heated hot gas tool. After a defined heating time, the changeover phase follows, in which the hot gas tool moves out of the heating zone, similar to hot plate welding, and the two joining parts are welded together either force- or displacement-controlled. The holding phase should be carried out at least until the entire joining seam has cooled down to a temperature below the melting temperature of the material in order to avoid damage to the joint produced. The component can then be removed.

The joining direction for hot gas butt welding can be either vertical or horizontal. In the horizontal mode of operation, the process gas flows onto the joining surfaces in a horizontal direction, and the joining direction is also horizontal (Fig. 1). In the vertical joining direction, the parts to be joined are located one above the other and are plasticized from above or below by the process gas along or against the force of gravity. The advantage of the vertical joining direction is that geometrically symmetrical melt layer profiles are produced, because there is no uneven melt flow due to the gravitational force lying parallel to the joining direction. However, when designing the process, it should be considered that the upper joining part can be heated up more than the lower joining part due to a stack effect.

\subsection{Challenges}

As process gas either an inert or an oxidizing gas can be used to plasticize the joining surfaces by convection. Welding in the presence of an oxidizing gas can, however, as in infrared welding [7], lead to excessive thermaloxidative degradation of the material and thus to a deterioration of the mechanical weld properties. However, the use of an inert gas, such as nitrogen, leads to increased operating costs. In order for users of the process to be able to make the best economic choice, it is necessary to know which materials do not require the use of an inert gas. Heating by hot gas offers the typical advantages of non-contact heating, is also suitable for high-temperature thermoplastics, and does not produce any particles via abrasion. However, due to the low heat transfer coefficient, the gas temperatures required are between 350 and $550{ }^{\circ} \mathrm{C}$, which are significantly higher than the melting temperatures of the materials, i.e., in the range of the thermally induced degradation of the materials. A distinction is made between purely thermal degradation, where chain splitting occurs due to high temperatures, and thermal-oxidative degradation. This occurs at high temperatures and in the presence of oxygen and, in addition to chain splitting, branching, and cross-linking, can result in a change in the chemical composition of the plastic. While thermal degradation in an inert atmosphere only occurs at high temperatures (e.g., for PC starting at 340 ${ }^{\circ} \mathrm{C}$ ), even lower temperatures in an oxygen-containing atmosphere (e.g., for PC starting at $200{ }^{\circ} \mathrm{C}$ ) can cause oxidation reactions. The resulting reduction in molar mass and the change in molar mass distribution and a splitting off of low-molecular products (depolymerization, side group splitting) have a negative effect on the mechanical properties of the plastic [10-15].
Fig. 1 Principle of horizontal hot gas butt welding with joining parts (1), hot gas butt welding tool (2), and process gas supply (3)

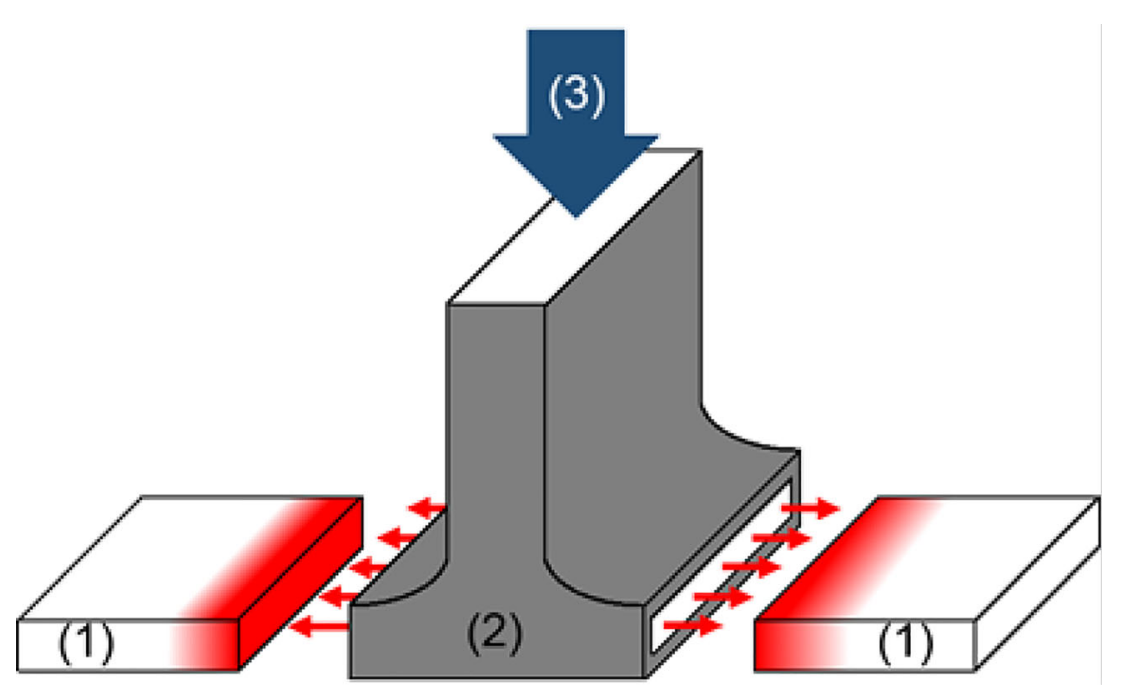


$[16,17]$ are the only scientific publications that have dealt with the heating behavior for welding of plastics by hot gas. A significant part of the work is attributed to theoretical and experimental research of hot gas preheating during extrusion welding, parameter influences, melt formation, material reactions, and the influence of nozzle shapes and jet behavior. However, the conditions and findings from continuous extrusion welding cannot be transferred to the static situation with two-sided mold part heating. At best, some basic findings, e.g., on the volume flow, the basic material reactions with regard to material degradation and the basically unfavorable heat transfer can be used for comparison. However, the investigations in these publications were only carried out with polyolefins, which are generally considered to be less prone to oxidation. It is known from extrusion technology that different material reactions can occur when polyamides are processed in inert or oxidative atmospheres [18]. A comparable behavior is also expected in hot gas butt welding.

Tests carried out with unreinforced and glass fiber reinforced polypropylene have shown that welding factors of 1 can be achieved with air as process gas [19]. The welding factor of a welded sample is the quotient of the weld strength and the material strength and is used to evaluate the quality of the welded joint. Ideally, the welding factor is 1 , in which case, the weld does not represent a local weakness in the entire component [20]. To determine which polyamides can be welded with which process gas, extensive experimental investigations were also carried out with air and nitrogen and various polyamides. The motivation for these investigations is that the use of air as process gas leads to a significant reduction of process costs.

\section{Experimental}

\subsection{Materials}

The materials selected for the experimental investigations (Table 1) are used industrially in many areas. For the investigations, plate specimens with the dimensions $130 \mathrm{~mm} \times 70 \mathrm{~mm} \times 4 \mathrm{~mm}$ were produced by injection molding. The material strengths for the materials after the injection molding process were determined experimentally on five unwelded specimens to enable the calculation of welding factors according to guideline 2203-5 (testing of welded joints of thermoplastics plates and tubestechnological bend test) of the DVS. All materials were dried before injection molding and joining, each according to the manufacturer's specifications.

\subsection{Experiment setup and procedure}

A hot gas butt welding tool from KVT Bielefeld $\mathrm{GmbH}$ (Fig. 2, left) was used for force-controlled welding of the test specimens. Within this tool, the process gas absorbs energy at the heated surfaces by convection and is thus heated to a maximum temperature of $550{ }^{\circ} \mathrm{C}$. Then, the process medium flows through round nozzles with a defined volume flow onto the surfaces to be joined and generates the required melt layer thickness. In order to reduce the influence of the residual melt layer thickness on the weld strength, force-controlled welding was used.

In order to reduce the number of experiments, design of experiment (DoE) is used for the welding tests. To optimize the system response (tensile strength) as a function of several continuous or discrete parameters (see Table 2), the split-plot response surface method (RSM) was used with an I-optimal design that minimizes the average variance of the prediction. Response surface experiments address the prediction of a value from given parameters. A split-plot design is chosen because the temperature in the welding experiments can only be changed with a larger amount of time. Therefore, grouped temperatures (whole plots) are created by the program, in which heating time and type of gas are varied (subplots). In contrast to the frequently used D-optimal design, an I-optimal design is used here, since very good predictions can subsequently be obtained for optimizing the tensile strength, while at the same time, the influence of the welding factors is precisely determined. Depending on the melting temperature of the material, the lower limits of gas temperature and heating time are selected to achieve sufficient weld strength and to test the tensile strength of the welded joint. For the three materials, it was determined in previous investigations that the optimum joining pressure is $0.19 \mathrm{~N} / \mathrm{mm}^{2}$. Therefore, the joining pressure was set to this value. The holding time was set to $45 \mathrm{~s}$ to
Table 1 Materials for the experimental investigations

\begin{tabular}{llll}
\hline Material & PA6 & PA66 heat-stabilized & PA6-GF30 \\
\hline Heat stabilization & No & Yes & No \\
Manufacturer & Lanxess & DuPont & BASF \\
Type & Durethan B30S & Zytel 103HSL NC010 & Ultramid B3EG6 \\
Determined material strength [MPa] & 77.4 & 81.2 & 114.0 \\
\hline
\end{tabular}


Fig. 2 Left: Test setup with hot gas butt welding tool. Right: Arrangement of round nozzles adapted to the weld seam geometry of the plate specimens

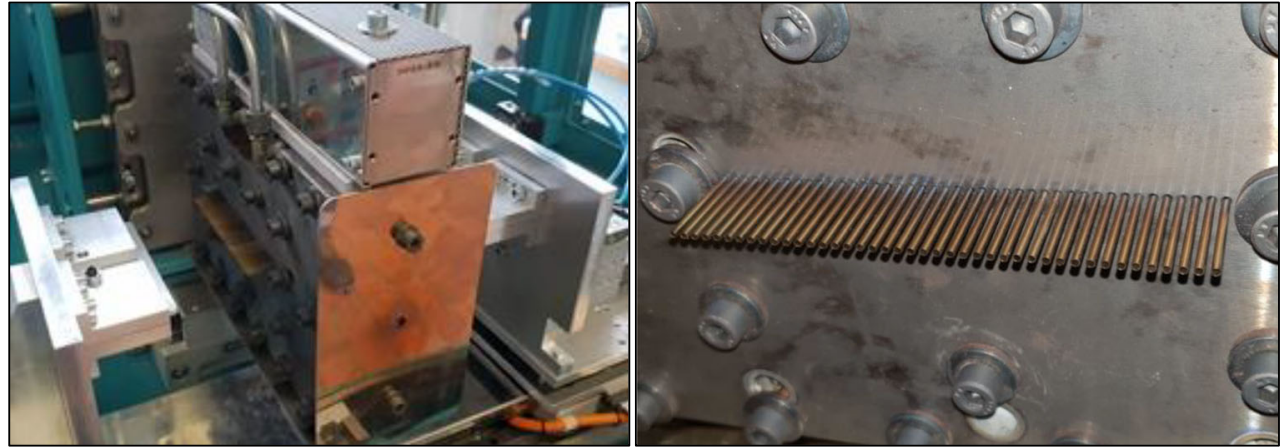

ensure cooling of the joining zone well below the melting temperature of the material before the welding part is removed from the machine. This prevents subsequent, unintentional damage to the welded joint.

Five welded joints were made per testing point in order to obtain a statement about the reproducibility. The welded test specimens were then prepared for the quasi-static tensile test with a sample saw in accordance with guideline 2203-2 (testing of welded joints between panels and pipes made of thermoplastics - tensile test) of the DVS. The flash was not removed. The tensile test was performed according to DIN EN ISO 527 at a test speed of $20 \mathrm{~mm} / \mathrm{min}$ on a Zwick Roell Z010 tensile testing machine with a $10 \mathrm{kN}$ load cell. To evaluate the weld seam quality, the measured tensile strengths were converted into welding factors with the help of the previously determined material strengths. When interpreting the results, it has to be considered that the flash was not removed before the tensile test so that they could contribute to an increase of the tested area. In addition, the coefficients of variation (relative standard deviation) were determined to assess the reproducibility of the welded joints. For reasons of clarity and because a statement about reproducibility is not the aim of these investigations, the coefficients of variation are described comparatively, but not shown

Table 2 Parameters of the welding process

\begin{tabular}{ll}
\hline Gas temperature $\left[{ }^{\circ} \mathrm{C}\right]$ & 400 to 550 \\
\hline Gas [-] & Air or nitrogen \\
Heating time [s] & 15 to 35 \\
Nozzle distance $[\mathrm{mm}]$ & 2 \\
Joining pressure $\left[\mathrm{N} / \mathrm{mm}^{2}\right]$ & 0.19 \\
Volumetric flowrate per & 0.0577 \\
$\quad$ joining surface area $\left[1 /\left(\mathrm{min}^{2} \mathrm{~mm}^{2}\right)\right]$ & 45 \\
Holding time $[\mathrm{s}]$ & $<1.5$ \\
Changeover time $[\mathrm{s}]$ & \\
\hline
\end{tabular}

graphically. The microscopic images of the fracture surfaces were taken with a Keyence VHX-600 microscope under reflected and polarized light.

To be able to make a statement about the service life of the manufactured connections, the manufactured connections of PA6 were also tested in a thermal shock test. The test parameters shown in Table 3 were used for this purpose. This setup simulates an aging of about 10 years for applications in the engine compartment of a motor vehicle (Karger O, HELLA $\mathrm{GmbH} \& \mathrm{Co}$. KGaA, personal communication, October 23, 2019). The results of PA6 before and after the thermal shock test are not described in welding factors as the material strength cannot be used as a basis for the calculation.

\section{Results}

In the following, the results of the experimental investigations for the tested materials are presented and explained. In each case, information on the statistical significance of the model parameters and the degree of fit of the data to the model polynomial is first provided in order to assess the quality of the models generated. To determine the significance of the individual influencing factors, the $p$-values of the model are analyzed. If the $p$-value is less than or equal to the significance level $\alpha=0.05$, a statistically significant association of the influencing factor with tensile strength is identified.

\subsection{PA6}

The $R^{2}$ of $98.86 \%$ means that more than $98 \%$ of the variance in tensile strength is explained by variation in the tensile

Table 3 Parameters of the thermal shock test

\begin{tabular}{ll}
\hline Upper temperature $T_{\mathrm{u}}\left[{ }^{\circ} \mathrm{C}\right]$ & +125 \\
\hline Lower temperature $T_{1}\left[{ }^{\circ} \mathrm{C}\right]$ & -40 \\
Number of cycles [-] & 500 \\
Cycle duration [min] & 60 \\
\hline
\end{tabular}


Table 4 Statistical significance of the model terms for PA6

\begin{tabular}{ll}
\hline Model term & $p$-value \\
\hline A (gas temperature) & 0.2419 \\
B (heating time) & 0.0841 \\
C (gas) & 0.0004 \\
D (thermal shock test) & 0.0001 \\
AB & 0.2898 \\
AC & 0.1304 \\
AD & 0.3066 \\
BC & 0.1554 \\
BD & 0.9359 \\
CD & 0.0001 \\
$\mathrm{~A}^{2}$ & 0.3652 \\
$\mathrm{~B}^{2}$ & 0.0311 \\
\hline
\end{tabular}

Italicize entries are statistically significant.

strengths considered. The adjusted $R^{2}$ of $95.07 \%$ indicates that every factor contributed to an improvement in the prediction of the tensile strength. In summary, these parameters indicate a very good fit of the model to the model polynomial. The information about the statistical significance of the model parameters are given in Table 4.

The comparison of the results welding with air and nitrogen without the influence of the thermal shock test (Fig. 3, left) shows that welding with nitrogen as

process gas achieves approximately twice as high weld strengths as when using air. The results for air show tensile strengths between 28 and $38 \mathrm{MPa}$ for the parameters investigated, which corresponds to a welding factor between 0.4 and 0.5 . When using nitrogen, short heating times and low gas temperatures result in the highest tensile strength of about $85 \mathrm{MPa}$, which corresponds to a welding factor of 1.1. Welding factors for nitrogen are higher than 0.9 over the entire test area. At high temperatures and long heating times, the lowest tensile strength of approx. $60 \mathrm{MPa}$ is achieved, which indicates increased thermal material damage. This is also clearly shown by a strong brown coloration of the material in the weld seam (Fig. 4). Furthermore, it was found that the coefficients of variation with nitrogen are significantly lower than with air, and the reproducibility of the weld is therefore better with nitrogen.

The comparison of the results of air-welded joints before and after the thermal shock test shows that the tensile strengths over the entire test range are only slightly reduced due to the influence of the thermal shock test (Fig. 3, upper). The coefficient of variation remains almost constant. By contrast, the tensile strengths determined for the nitrogen-welded samples are significantly reduced by about $30 \%$ for all process parameters (Fig. 3, lower). In addition, the coefficients
Fig. 3 Tensile strength of PA6 in the short-term tensile test without thermal shock test (left) and after thermal shock test (right), both heated with air (top) and nitrogen (bottom)

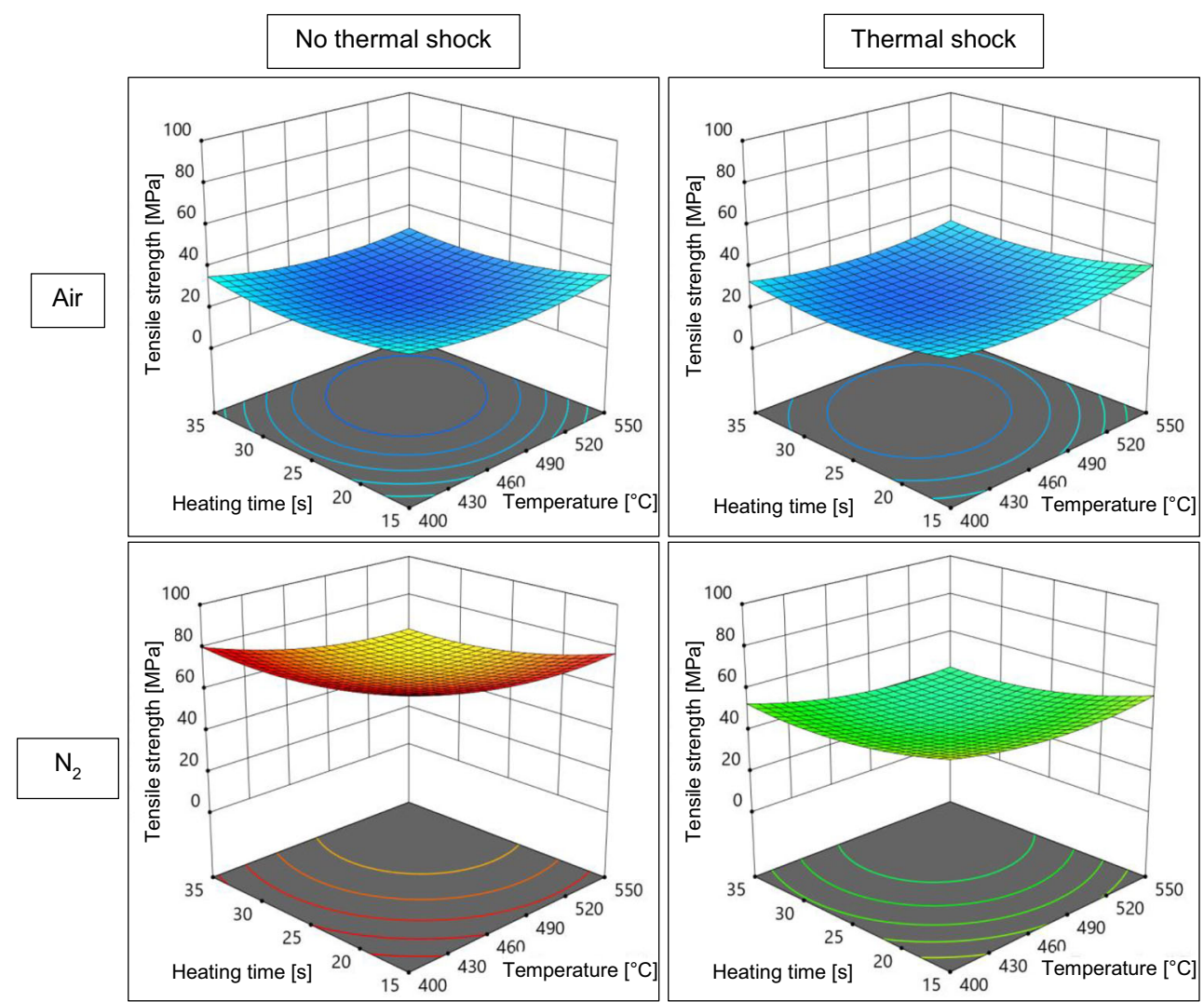



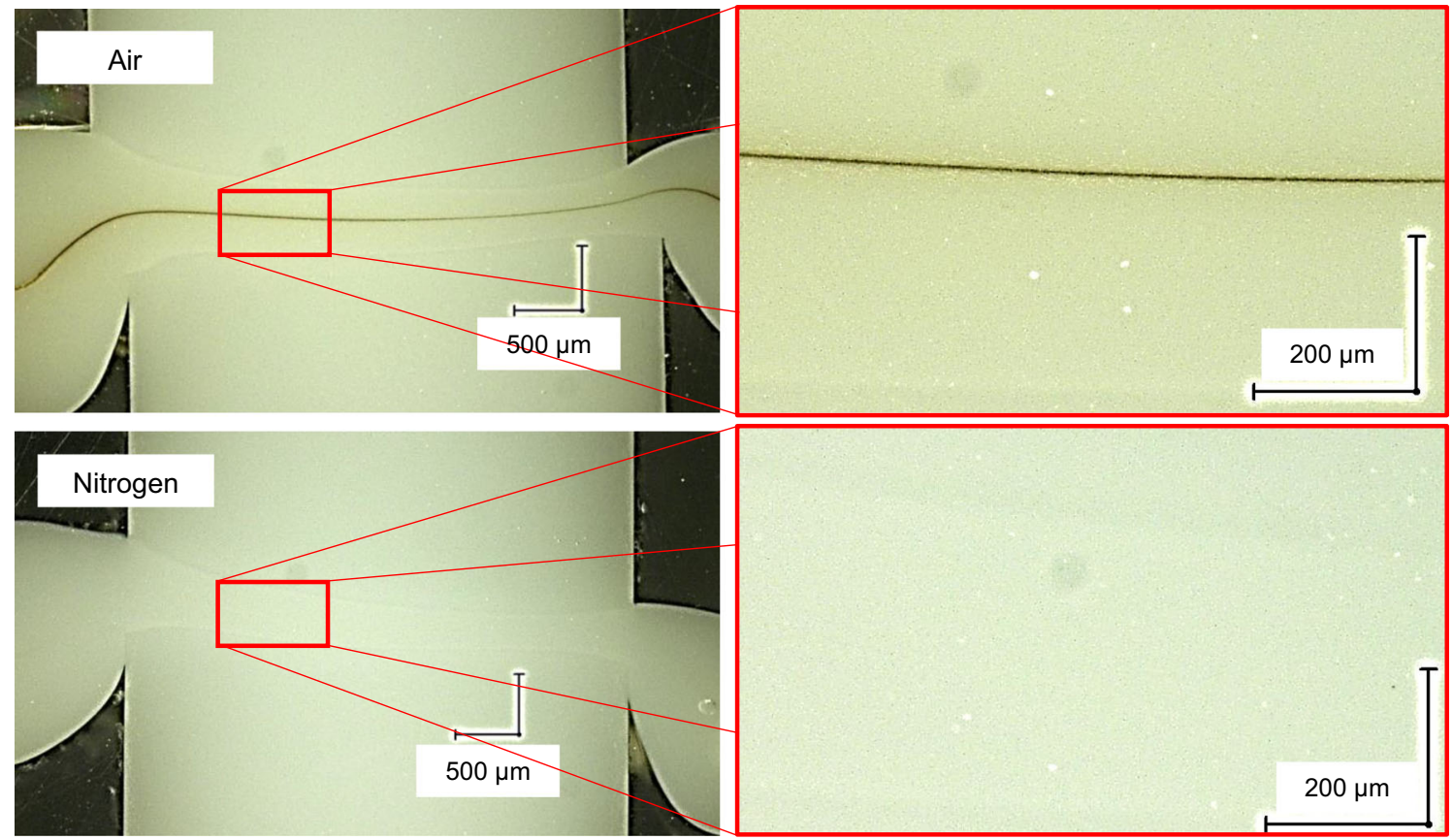

Fig. 4 Microscopy of PA6 weld seams, heated with air (top) and nitrogen (bottom); $T_{\mathrm{g}}=550^{\circ} \mathrm{C}, t_{\mathrm{h}}=19 \mathrm{~s}$

of variation are significantly increased by the influence of the thermal shock test with nitrogen. During the thermal shock test, no welded joints were broken due to the direct influence of the temperature differences.

\subsection{PA66 heat-stabilized}

The $R^{2}$ of $87.31 \%$ means that more than $87 \%$ of the variance in tensile strength is explained by variation in the tensile strengths considered. The adjusted $R^{2}$ of $46.74 \%$ indicates that almost half of the factors contributed to an improvement in the prediction of the tensile strength. In summary, these parameters indicate a good fit of the model to the model polynomial. The information about the statistical significance of the model parameters are given in Table 5.

Table 5 Statistical significance of the model terms for PA66 heatstabilized

\begin{tabular}{ll}
\hline Model term & $p$-value \\
\hline A (gas temperature) & 0.0322 \\
B (heating time) & 0.0711 \\
C (gas) & 0.8008 \\
AB & 0.9346 \\
AC & 0.9276 \\
BC & 0.9052 \\
$\mathrm{~A}^{2}$ & 0.4933 \\
$\mathrm{~B}^{2}$ & 0.3573 \\
\hline
\end{tabular}

Italicize entries are statistically significant.
The results of experimental investigations with heatstabilized PA66 show that very similar welding factors are achieved with both nitrogen and air (Fig. 5). Especially at low gas temperatures of $400{ }^{\circ} \mathrm{C}$ and long heating times of $35 \mathrm{~s}$, welding factors of about 0.6 are obtained, where the melt layer is produced with materialfriendly process parameters. In particular, the long heating time results in a large melt layer thickness. In forcecontrolled joining, this allows the material near the surface, which is thermally or thermally-oxidatively most degraded, to be displaced into the flash. As a result, the joint is created by less damaged material. Furthermore, it was found that the coefficients of variation are slightly higher for welded joints produced with air.

The fracture surfaces of the heat-stabilized PA66 after the tensile test are shown in Fig. 6. With a short heating time of $15 \mathrm{~s}$ (Fig. 6, left), a smaller melt layer thickness is built up, so that after joining, residues of the highly degraded material (brown discoloration) remain in the weld seam, as they are not completely displaced into the flash. Due to the force-controlled welding process, it is assumed that the residual melt layer thickness remaining in the weld seam after the joining process is approximately the same at both test points. When a larger melt layer is produced by the heating time of $35 \mathrm{~s}$ (Fig. 6, right), there are no thermally damaged brown residues on the fracture surface. It is proven that the thermally or thermally-oxidatively most damaged material is displaced into the flash during the joining process by the resulting squeezing flow. This results in a slightly higher weld strength at constant gas temperature 
Fig. 5 Welding factors of heatstabilized PA66 heated with air (left) and nitrogen (right) in a short-time tensile test
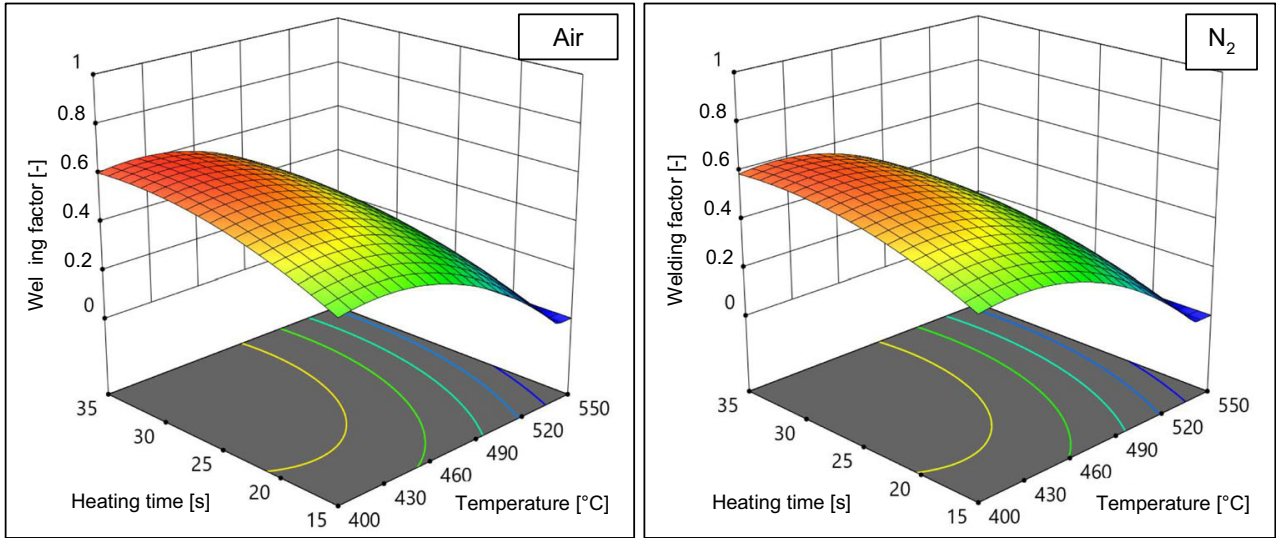
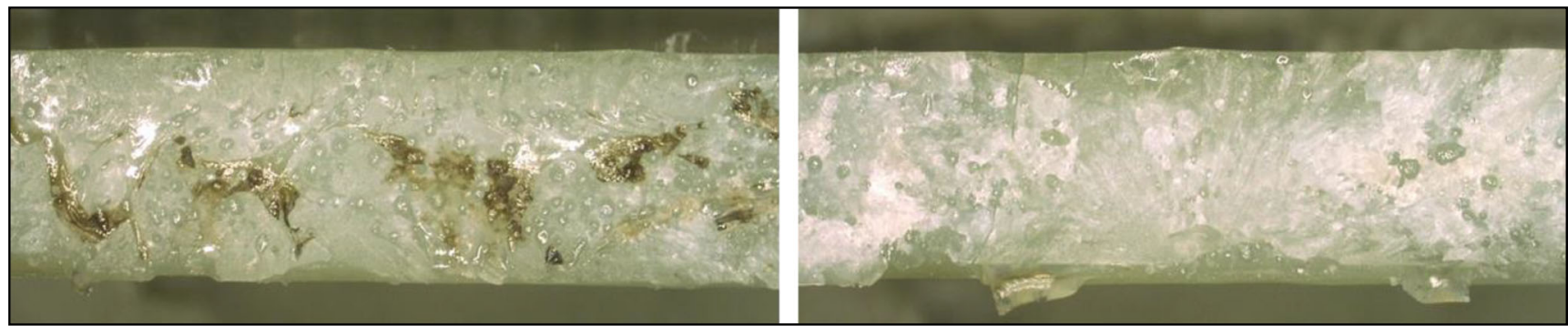

Fig. 6 Fracture surfaces of heat-stabilized PA66 welded with air at $T_{\mathrm{g}}=550{ }^{\circ} \mathrm{C}$; left: $t_{\mathrm{h}}=15 \mathrm{~s}$; right: $t_{\mathrm{h}}=35 \mathrm{~s}$

for longer heating times. The difference in the qualitative behavior of the tensile strengths as a function of the varied process parameters between PA6 and heat-stabilized PA66 can be explained by the higher melt viscosity of PA6. This results in a completely different flow behavior of the melts during joining.

\subsection{PA6-GF30}

The $R^{2}$ of $95.09 \%$ means that more than $95 \%$ of the variance in tensile strength is explained by variation in the tensile strengths considered. The adjusted $R^{2}$ of $78.72 \%$ indicates that a large part of the factors contributed to an improvement in the prediction of the tensile strength. In summary, these parameters indicate a good fit of the model to the model polynomial. The information about the statistical significance of the model parameters are given in Table 6.

The results of the experimental investigations of PA6GF30 are shown in Fig. 7. They show that the highest welding factors are generated with both air and nitrogen at medium gas temperatures of approx. 480 to $500{ }^{\circ} \mathrm{C}$. When welding with air, similar to the heat-stabilized PA66, the longest possible heating times should be selected to produce a large melt layer thickness in order to displace the surface-near, thermally or thermally-oxidatively degraded material into the flash. When welding with nitrogen, high welding factors of about 0.8 are

achieved with medium temperatures and all heating times. Here, as a result of the inert gas, no excessive thermaloxidative dame occurs, so that the surface material does not necessarily have to be displaced into the flash to achieve a high weld seam quality. The difference in the qualitative behavior of the tensile strengths as a function of the varied process parameters between PA6 and PA6-GF30 can be explained by the higher thermal conductivity of the glass fiber reinforced material. As a result, a greater melt layer thickness can be produced in PA6-GF30 with the same process parameters, which influences the squeeze flow and hence also the fiber orientation in the welded joint.

Table 6 Statistical significance of the model terms for PA6-GF30

\begin{tabular}{lc}
\hline Model term & $p$-value \\
\hline A (gas temperature) & 0.0696 \\
$\mathrm{~B}$ (heating time) & 0.0256 \\
$\mathrm{C}$ (gas) & 0.0011 \\
$\mathrm{AB}$ & 0.1058 \\
$\mathrm{AC}$ & 0.0117 \\
$\mathrm{BC}$ & 0.0555 \\
$\mathrm{~A}^{2}$ & 0.1511 \\
$\mathrm{~B}^{2}$ & 0.2199 \\
\hline Italicize entries are statistically significat.
\end{tabular}

Italicize entries are statistically significant. 
Fig. 7 Welding factors of PA6GF30 heated with air (left) and nitrogen (right)

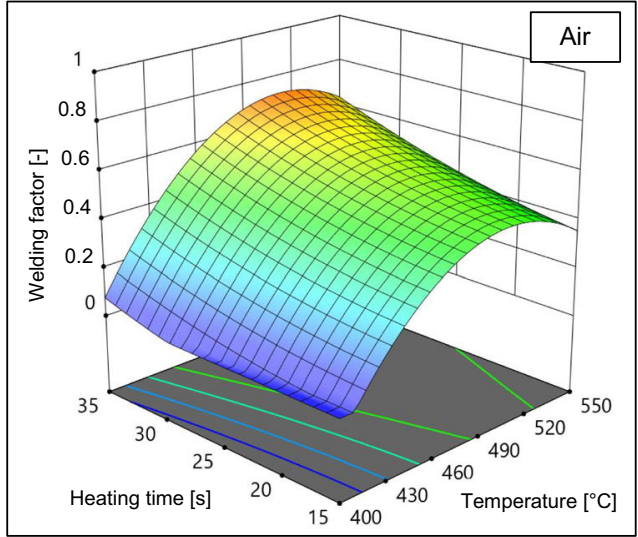

\section{Summary and conclusion}

Experimental investigations with non-heat-stabilized PA6 and PA6-GF30 have shown that using nitrogen as a process gas, higher weld strengths can be achieved with lower coefficients of variation than when using air. A reduction of the weld strengths can be prevented when welding the glass fiber reinforced PA6 with air by extending the heating time. This process management causes the excessively damaged material to be pressed from the joint surface into the flash, so that the welded joint is produced by less degraded material. However, the cycle time extension would again lead to an increase in unit costs. Which influencing factor has a greater economic impact here, the cycle time extension or the use of an inert gas, should always be checked individually for the relevant product. In some cases, the presence of a flash may not be desired. So, choice of a process that uses the flash as a way of carrying away the degraded material may not be allowed. Flash traps could be used as a solution to this problem. In addition, it was shown that the use of nitrogen for a heat-stabilized PA66 does not improve weld strength, and therefore air can be used as a process gas for this material. The results of thermal shock tests on non-heat-stabilized PA6 have shown that only the tensile strengths of nitrogen-welded joints are reduced, by about $30 \%$, but they still show acceptable welding factors. These welds are still significantly stronger than those produced with air as a processing gas.

Abbreviations DVS, German Welding Association; PA6, Polyamide 6; PA66, Polyamide 6.6; PA6-GF30, Polyamide 6, 30\% glass fiber reinforced; PC, Polycarbonate; $T_{\mathrm{g}}$, gas temperature; $t_{\mathrm{h}}$, heating time

Acknowledgements The IGF Project 20119 B of the research association "Forschungsvereinigung Schweißen und verwandte Verfahren e.V. des DVS. Aachener Straße 172. 40223 Düsseldorf" was, on the basis of a resolution of the German Bundestag, promoted by the German Ministry of Economic Affairs and Energy via AiF within the framework of the program for the promotion of joint industrial research and development (IGF).

Funding Open Access funding enabled and organized by Projekt DEAL.

Open Access This article is licensed under a Creative Commons Attribution 4.0 International License, which permits use, sharing, adaptation, distribution and reproduction in any medium or format, as long as you give appropriate credit to the original author(s) and the source, provide a link to the Creative Commons licence, and indicate if changes were made. The images or other third party material in this article are included in the article's Creative Commons licence, unless indicated otherwise in a credit line to the material. If material is not included in the article's Creative Commons licence and your intended use is not permitted by statutory regulation or exceeds the permitted use, you will need to obtain permission directly from the copyright holder. To view a copy of this licence, visit http://creativecommons.org/licenses/by/4.0/.

\section{References}

1. Fuhrich R, Gehde M, Friedrich S (2011) Mechanische Eigenschaften von Infrarotschweißverbindungen. Joining Plastics 3(4):216-221

2. Belmann A (2017) Kontaminationsreduktion beim Fügen von Kunststoffen. Joining Plastics 1:34-41

3. Fuhrich R (2012) Infrarotschweißen von Kunststoffen mit thermischen Strahlungsemittern. Dissertation, Chemnitz University of Technology

4. Constantinou M, Gehde M, Dietz R (2015) Emitter-material-a complex system. Presentation at $5^{\text {th }}$ FRIMO TechDay - Plastics Joining. June 11, 2015, Hamburg

5. Ehrenstein GW (2004) Handbuch Kunststoff-Verbindungstechnik. Hanser Verlag, München

6. Rattke M, Natrop J (2008) Neu entwickeltes Konvektionsschweißverfahren auf Erdgasbasis. Joining Plastics 2:129-133

7. Mochev S, Endemann U (2016) Mehr als nur heiße Luft. Kunststoffe 12:76-79

8. Albrecht M, Gehde M, Bialaschik M, Schöppner V (2019) Einfluss des Werkzeugdesigns auf das Erwärmverhalten beim Warmgasschweißen. Presentation at Technomer. November 7, 2019, Chemnitz

9. Mochev S, Endemann U (2018) Schneller und besser Schweißen. Kunststoffe 9:122-125 
10. Bauer E, Brinkmann S, Osswald TA, Schmachtenberg E (2007) Seachtling Kunststoff-Taschenbuch, 30. Auflage edn. Carl Hanser Verlag, München

11. Bonnet M (2014) Kunststofftechnik. Springer Verlag, Wiesbaden

12. Ehrenstein GW, Pongratz S (2007) Beständigkeit von Kunststoffen, Band 1. Carl Hanser Verlag, München

13. Hawkins WL (1964) Thermal and oxidative degradation of polymers. Polym Eng Sci 4(3):187-190

14. Krebs C, Avondet M, Leu W (1999) Langzeitverhalten von Thermoplasten - Alterungsverhalten und Chemikalienbeständigkeit. Hanser Verlag, München

15. Pongratz S (2000) Alterung von Kunststoffen während der Verarbeitung und im Gebrauch. Dissertation, University of Erlangen-Nuremberg

16. Gehde M (1993) Zum Extrusionsschweißen von Polypropylen. Dissertation, University of Erlangen-Nuremberg
17. Heil M, Michel P, Potente H (1988) Prozessanalyse und optimierung des Extrusionsschweißens. Final report on research project IV B5 20400985, Kunststofftechnik Paderborn, University of Paderborn

18. Pongratz S, Duriau-Montagne F, Ehrenstein G (2000) Einfluss der Verarbeitung auf den Abbau von PA und PP. Kunststoffe 2:52-55

19. Bialaschik M, Schöppner V (2019) The influence of oxidising and inert gases on the weld seam quality in hot gas welding. Presentation at IIW 2019, Commission XVI - Polymer Joining and Adhesive Technology. July 9, 2019, Bratislava

20. Potente H (2004) Fügen von Kunststoffen. Carl Hanser Verlag, München, Wien

Publisher's note Springer Nature remains neutral with regard to jurisdictional claims in published maps and institutional affiliations. 